\title{
Airway management for general anesthesia in patients with rheumatic diseases - new possibilities
}

\author{
Tomasz Gaszyński \\ Department of Anaesthesiology and Intensive Therapy, Medical University of Lodz, Poland
}

Airway management for general anesthesia in patients with rheumatic diseases can be very challenging because of changes related to the disease, especially in temporomandibular joints and the cervical spine.

In this case airway and neck assessment is crucial; atlanto-axial subluxation can be detected and there is a potential risk of spinal cord damage when performing airway management. For most cases awake fibreoptic intubation may be required for airway management, which is considered as the standard approach [1].

Changes in the cervical spine include sclerosis, discopathy, and instability of vertebral joints with the possibility of subluxations. The conditions may be complicated by previous surgery for stabilization of the cervical spine and discopathy treatment. Changes in joints can be related to several rheumatoid diseases. For airway management inflammation of temporomandibular joints and vertebral joints in the cervical spine is important.

For airway management, the implication will be especially the reduction of mouth opening and a commonly occurring cervical stiffness that make both the intubation procedures and the positioning of head and neck difficult. For evaluation one may use the Mallampati score, mouth opening and mandible protrusion as preoperative predictors of temporomandibular dysfunction.

Cricoarytenoid dysfunction is another factor influencing difficulties related to airway management. The larynx may be affected in approximately $80 \%$ of patients. The symptoms may be presented as foreign body sensation in the oropharynx, dysphagia, dyspnea, hoarseness, stridor, and also by airway obstruction. As possible diagnosis during visualization of the larynx may reveal cricoarytenoid and vocal cord dysfunction during inspiration.

For patients with this disease fiberoptic nasoendoscopy is recommended and the use of a tracheal tube with a small diameter that can provide appropriate ventilation. It is important to avoid trauma of the la- ryngeal structures. For safe extubation the removal of the tracheal tube should take place in an appropriate environment prepared for emergencies. In some cases even preventive preoperative tracheostomy should be considered [2].

The use of fiber optic bronchoscopy is recommended in such cases, because it allows adequate access to the airways with minimal cervical mobilization. Awake intubation should be considered but it requires a suitably trained anesthesiologist, with minimal sedation.

The occurrence of ankylosis of the temporomandibular joint poses additional risk during airway management for anesthesia, because the occurrence of small mouth openings to less than $2 \mathrm{~cm}$ is possible. In these cases the use of a flexible fiber optic bronchoscope is recommended.

As an alternative to endotracheal intubation the use of a laryngeal mask airways can be considered, which provides airway protections with less airway trauma. However, there are reports that its use can worsen the symptoms of cricoarytenoid involvement.

Some authors suggest for preanesthesia airway evaluation indirect laryngoscopy.

The atlanto-axial joint is commonly affected. Acute subluxation may cause spinal cord compression and/or compression of the vertebral arteries leading to quadriparesis or sudden death during airway management attempts.

The temporomandibular joint (TMJ) may be involved, causing limitation of mouth opening and rendering direct laryngoscopy impossible.

For general anesthesia the airway may be managed in several ways: the laryngeal mask airway (LMA) can be effectively used [3]. However, it may be difficult to insert an LMA if the angle between the oral and pharyngeal axes at the back of the tongue is less than 90 degrees. Retrograde intubation may also be considered.

\section{Address for correspondence:}

Tomasz Gaszyński, Department of Anaesthesiology and Intensive Therapy, Medical University of Łódź, 22 Kopcińskiego St., $91-153$ Łódź, Poland, e-mail: tomasz.gaszynski@umed.lodz.pl

Submitted: 15.04.2019; Accepted: 17.04.2019 
The choice to perform tracheal intubation for general anesthesia should depend on an assessment of the risks of gastric aspiration, and the type and duration of surgery. As tracheal intubation is indicated, it must be achieved without causing further injury to a potentially unstable cervical spine. The manipulation of the neck during airway management attempts can lead to neurological deterioration, tetraplegia and even sudden death and thus should be avoided. When trying to position the patient's head in recommended "sniffing" position for direct laryngoscopy, when the head is hyperextended on a flexed neck it can result in exacerbation of the anterior atlanto-axial subluxation with resultant neurological injury. Therefore during conventional laryngoscopy and neck manipulation special care must be considered, even without overt cervical spine instability.

An intubating LMA (ILMA) may be used to achieve blind endotracheal intubation with minimal cervical spine movement, but the poor success rate without the use of fiber optics and the great amount of force that may be exerted on the posterior wall of the pharynx at C2-C3 make the ILMA not recommended as a primary method of intubation [4].

Fibreoptic intubation is proved to provide the safety of airway management in an awake intubation method and is highly recommended. These efforts are employed to prevent hyperextension of the neck, a common occurrence in airway maneuvers. Unfortunately, an awake fibreoptic intubation often is performed not without problems and depends on the skill of the operator [5].

A surgical tracheostomy performed under local anesthesia can be considered a method of securing the airway of patients with cricoarytenoid involvement. However, potential difficulties with this method include the presence of an extreme fixed flexion deformity with little or no access to the trachea, tracheal deviation and patient distress [6].

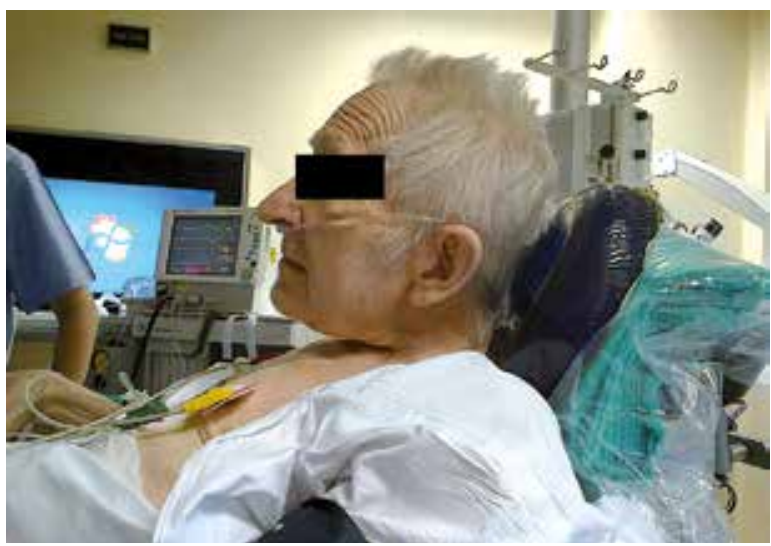

Fig. 1.
As mentioned above, the method of first choice for airway management in patients with rheumatoid diseases scheduled for general anesthesia still fiberoptic intubation is considered. Unfortunately fiberoptic intubation requires adequate equipment and skills of the operator. There is an alternative for fiberoptic intubation if endotracheal intubation is recommended: videolaryngoscopes and rigid optic intubation stylets. Videolaryngoscopes are easier to use with the same effectiveness of intubation as fibroscopes. Most anesthesiologists can effectively use videolaryngoscopes after a short training period, in contrast to fiberoptic intubation, which requires long training. Videolaryngoscopes are easier because they can be used similarly to standard laryngoscopes.

The Glidescope (GS) (Saturn Biomedical System Inc., Burnaby, BC, Canada) is reported as a useful device that improved visualization of the larynx and facilitated naso-tracheal intubation. The GS improved the laryngoscopic view in all patients and nasal intubation was successful in most of the patients. The main limitation of the GS is the resistance encountered during advancement of the tracheal tube [7].

To overcome the obstacles that may occur in a difficult intubation, an endotracheal introducer able to facilitate the passage of the endotracheal tube through the vocal cords into the trachea may be useful [8].

A novel technique of endotracheal intubation is used for the successful airway management during the surgical treatment in patients with temporomandibular joint ankylosis with the assistance of a fiberscope and GlideScope videolaryngoscope [9]. This technique avoids complications such as trauma to soft tissue structures surrounding the glottis during the passage of the tube over the fiberscope. It gives a clear view of the tube and its cuff position during intubation. Other videolaryngoscopes can also be used such as the McGrath videola-

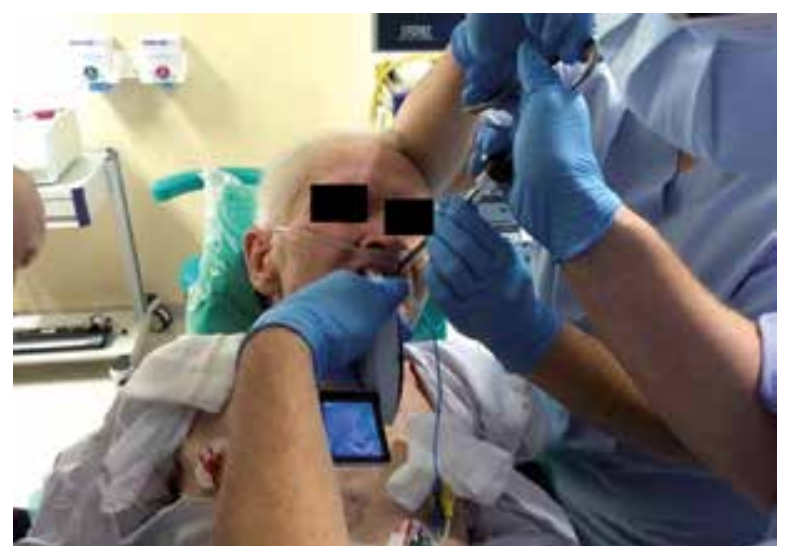

Fig. 2. 
ryngoscope for awake intubation in patients with severe ankylosing spondylitis [10].

Our experience shows that the McGrath Mac videolaryngoscope (Medtronic, USA) can be used successfully in patients with rheumatoid diseases. We managed a few cases of patients with ankylosing spondylitis using the McGrath Mac videolaryngoscope as alternative to fiberoptic intubation. In the case presented in Figures 1 and 2 the videolaryngoscope allowed for face-to-face approach technique, similarly to fiberoptic intubation.

Rigid optic intubation stylets can be used similarly to standard intubation stylets so it is easier for most anesthesiologists to learn fast how to operate them. They are especially useful in patients with limited mouth opening.

In summary, airway management in patients with rheumatic diseases requires an individualized approach plan. The choice of method is based on the patient's condition, airway evaluation, available equipment, skills of the operator and predicted postoperative airway challenges. New devices such as videolaryngoscopes can provide an easy learning curve, with comparable effectiveness and safety to standard fiberoptic intubation.

The author declares no conflict of interest.

\section{References}

1. Ćwiek R, Lisowska B, Małdyk P. Ocena przydatności znieczulenia przewodowego do operacji ortopedycznych $u$ chorych $z$ chorobami reumatycznymi. Reumatologia 2006; 44: 145-149.
2. Fombon FN, Thompson JP. Anaesthesia for the adult patient with rheumatoid arthritis. Continuing Education in Anaesthesia. Critical Care Pain 2006; 6: 235-239.

3. Kido H, Komasawa N, Deguchi S, Minami T. Successful LMA-ProSeal insertion using a tracheal tube introducer in a patient with severe rheumatoid arthritis. J Clin Anesthesia 2016; 33: 501-502.

4. Lu PP, Brimacombe J, Ho AC, et al. The intubating laryngeal mask airway in severe ankylosing spondylitis. Can J Anaesth 2001; 48: 1015-1019.

5. Olewicz-Gawlik A, Hrycaj P. Znieczulenie w chorobach reumatycznych - spojrzenie reumatologa. Anestezjologia i Ratownictwo 2010; 4: 474-478.

6. Airesa RB, de Carvalho JF, da Mota LMH. Pre-operative anesthetic assessment of patients with rheumatoid arthritis Rev Bras Reumatol 2014; 54: 213-219.

7. Woodward LJ, Kam PCA. Ankylosing spondylitis: recent developments and anaesthetic implications. Anaesthesia 2009; 64: 540-548.

8. Ciccozzi A, Angeletti C, Guetti C, et al. GlideScope and Frova Introducer for Difficult Airway Management. Case Rep Anesthesiol 2013; 2013: 717928.

9. Gupta A, Kapoor D, Awana M, Lehl G. Fiberscope Assisted Videolaryngoscope Intubation in the Surgical Treatment of TMJ Ankylosis. J Maxillofac Oral Surg 2015; 14: 484-486.

10. Uslu B, Nielsen RD, Kristensen BB. McGrath ${ }^{\oplus}$ videolaryngoscope for awake tracheal intubation in a patient with severe ankylosing spondylitis. Br J Anaesthesia 2010; 104: 118-119. 